\title{
Ex Post Evaluation of an Earmarked Tax on Air Pollution ${ }^{\star}$
}

\author{
Katrin Millock \\ EUREQua (CNRS-Université de Paris I) \\ Maison des Sciences Economiques \\ 106/112 Boulevard de l'Hôpital \\ 75647 Paris Cedex 13, France \\ Tel: +33 (0)1 44078203 \\ Fax: +33 (0)1 44078231 \\ email:millock@univ-paris1.fr \\ Céline Nauges \\ LERNA-INRA \\ Université de Toulouse I \\ 21 Allée de Brienne \\ 31000 Toulouse, France \\ Tel: +33 (0)5 61128517 \\ Fax +33(0)5 61128520 \\ email: cnauges@toulouse.inra.fr
}

\begin{abstract}
${ }^{\star}$ The authors are, respectively, with EUREQua, an economics research center of the CNRS and Université de Paris I, and LERNA, research center of INRA and Université de Toulouse I. We are grateful for helpful comments from two anonymous reviewers that improved the paper. We also thank Ujjayant Chakravorty, Carolyn Fischer, Thomas Sterner and seminar participants at INRA-Rennes, The Economics Department of Reading University, The Economics Department of Emory University, Atlanta, and the Agricultural and Resource Economics Department at UC Berkeley for comments on earlier versions of this paper. We gratefully acknowledge financial support by the CNRS and access to data from ADEME and SESSI. The conclusions expressed in this paper represent only the views of the authors.
\end{abstract}




\begin{abstract}
In this paper we do an ex post evaluation of the French tax on air pollution. The revenues of this tax were redistributed to polluters in the form of subsidies to abatement technologies, and the policy is a typical example of an earmarked tax. We use a two-stage estimation procedure on an unbalanced panel data set of 226 plants from three industrial sectors which are some of the main contributors to nitrogen oxide and sulfur dioxide emissions. The results indicate that the overall environmental effectiveness of this particular tax/subsidy scheme can be questioned.
\end{abstract}




\section{INTRODUCTION}

Failures in the market for environmental goods, such as those originating from externalities or asymmetric information, call for some regulatory actions. Economists have recommended different sorts of incentive-based instruments to correct for such inefficiencies: taxes, pollution permits, or subsidies. However, practical implementation of such instruments can be delicate for different reasons: polluters may be difficult to identify, pollution may not be directly measurable, or taxation may run into political constraints (see Buchanan and Tullock 1975, or McKibbin and Wilcoxen 2002, for a recent application on why it is so difficult to implement a tax or tradeable permits for climate change policy). Actual policies thus frequently differ from what is recommended by theory. The analysis of second-best solutions and the effects that they actually produce are thus necessary guidelines for regulators who very often need to reduce resistance from targeted polluters. An example of such a second-best policy for air pollution can be found in Sweden where the polluters pay a charge on nitrogen oxide $\left(\mathrm{NO}_{\mathrm{x}}\right)$ emissions and the revenues are returned to the same group of polluters in proportion to their production of useful energy (Sterner 2002). The French air

pollution tax is another example of a revenue-refunded instrument, of which the revenues are allocated to abatement subsidies that benefit the group of targeted polluters. ${ }^{1}$ Such systems combining a tax and a subsidy are commonly called "earmarked tax" systems. ${ }^{2}$

Existing theoretical analyses of environmental taxes have mainly been concerned with output-based refunding of environmental revenues, and ignored the case when revenue is returned in the form of abatement subsidies. For example, Fischer $(2001,2003)$ analyses the case when the revenue from taxes or auctioned tradeable permits is refunded to the firms according to their share of industry output. Although the same marginal incentive for emission reductions holds as under an emission tax, the firm will produce a higher level of output compared to the optimal solution. Consequently, for any given emission rate, outputbased rebating of emission taxes induces less emission reductions than would the optimal policy of a Pigouvian tax. ${ }^{3}$ In this sense, the analysis of output-based refunding is similar to the conclusions on the perverse effects of subsidies for abatement, which can lead to excessive entry and a lower output price than what would be socially optimal (Baumol and Oates 1988). When the output market is imperfectly competitive, however, Gersbach and Requate (2004) show that output-based refunding can improve social welfare. 
The contribution of this paper is an empirical analysis of an earmarked tax system, through the ex post evaluation in three industrial sectors of the French system of air pollution taxation with respect to its objective of lowering emissions by subsidizing abatement technologies. In many countries, ex ante evaluations of proposed policies are required, but ex post assessments of the efficiency of a policy after some years of implementation are quite rare. This is preoccupying since studies have found quite large discrepancies between predicted per unit abatement cost and actual costs of a policy, as well as between the predicted emission reduction and the actual emission reduction induced by policy (Harrington, Morgenstern and Nelson 2000). ${ }^{4}$ We wish to contribute to filling this gap, and help inform better policy as to the effects of different designs of environmental taxes. Our analysis uses a nine-year (1990-98) database of 226 plants from three industrial sectors (iron and steel, coke, and chemistry) which are among the main contributors to $\mathrm{NO}_{\mathrm{x}}$ and sulfur dioxide $\left(\mathrm{SO}_{2}\right)$ emissions in France. The results of our study indicate that, for these three sectors, the effectiveness of an earmarked tax scheme like that of the French tax on air pollution in the nineties can be questioned. For the three sectors in our sample, the tax had a negative impact on $\mathrm{NO}_{\mathrm{x}}$ and $\mathrm{SO}_{2}$ emissions. The combined subsidy, however, generally increased emissions significantly and to an extent that dwarfed the negative impact of the tax. These results contrast with the findings of Höglund (2000) and Sterner and Höglund (2000) regarding the evaluation of the Swedish earmarked emission tax on $\mathrm{NO}_{\mathrm{x}}$. In their discussion (there is no econometric analysis) on the effectiveness of the Swedish $\mathrm{NO}_{\mathrm{x}}$ charge, which is rebated on the basis of energy production, Sterner and Höglund (2000) argue that this policy proved effective as between 1992 and 1998, the 200 Swedish combustion plants that initially were targeted by the regulation reduced their average emission rates by $40 \%{ }^{5}$ We conclude our analysis by suggesting an explanation for the difference in effectiveness between the two regulations based on the nature of the abatement subsidy and the emissions monitoring system, rather than just simply a result of the difference in tax rates.

This study contributes to extending the scarce empirical literature on the actual effects of environmental taxes on air pollution, in contrast with the evaluations that have been performed on the US experience of tradeable emission permits, see for example Joskow, Schmalensee and Bailey (1998), Stavins (1998) and Carlson et al. (2000) on the sulfur emissions market, or Kerr and Newell (2003) on the tradeable permits used to phase out lead in gasoline. The few exceptions of ex post analyses of emission taxes for air pollution are Wang and Wheeler (1996), Millock and Nauges (2003), and Bruvoll and Larsen (2004). Wang and Wheeler (1996) use cross-section data on individual plants in 1993 to estimate the 
elasticity in the response to the Chinese pollution levy and find an elasticity of emissions of suspended particles (TSP) with respect to the pollution levy equal to $-0.65 .{ }^{6}$ While Wang and Wheeler (1996) find a significant effect of the Chinese levy on emissions of TSP, Bruvoll and Larsen (2004) found a less optimistic result as concerns the effectiveness of the Norwegian carbon tax. In an evaluation of the Norwegian carbon tax over the period 1990-99 using general equilibrium simulations, they find that the carbon tax accounted only for a small share of emission reductions over the period studied due to the exemptions accorded to several energy-intensive sectors. A preliminary empirical evaluation of the French tax/subsidy scheme is found in Millock and Nauges (2003) who do a simple estimation of the effect of the tax by regressing emissions on the tax rate, the Brent index of oil prices, regional GDP and dummy variables for industrial sector. The elasticity of emissions with respect to the tax rate was found to be significant and equal to -0.15 for $\mathrm{NO}_{2}$ emissions and -1.40 for $\mathrm{SO}_{2}$ emissions. This is a partial estimation of the tax, however, since it does not include the effect of the subsidies paid out of the tax revenues. In addition, we use a different and richer data set here since we have combined the emissions data with further data on individual plant characteristics.

Other studies that are related to this article for their use of ex post data for evaluation of environmental policy are Khanna and Damon (1999) and Björner and Jensen (2002). Both papers are concerned with the evaluation of a combination of voluntary programs and traditional regulation (norms, or taxes and subsidies). Khanna and Damon (1999) evaluate the impact of EPA's voluntary 33/50 Program on toxic releases during its first 3 years, 19911993. Björner and Jensen (2002) analyze a combination of the Danish $\mathrm{CO}_{2}$ tax, voluntary agreements and subsidies to investments in energy reduction and find a significant reduction in energy demand from the Danish voluntary agreements, as well as from the carbon tax. All the above studies show the importance of the design of the policy instrument, that is, the existence of a strong background threat of alternative regulation in the case of voluntary programs, or design features such as tax exemptions for some sectors. The importance of these institutional features of tax design is confirmed in our study.

The paper is organized as follows. Section 2 describes the regulatory framework in which French plants operate. In Section 3, we analyze theoretically the optimal behaviour of a representative firm under the French system of air pollution regulation. The data set and the econometric analysis are presented in Section 4. Section 5 concludes and discusses some policy implications. 


\section{REGULATORY FRAMEWORK}

The French tax on air pollution (la taxe parafiscale sur la pollution atmosphérique, or TPPA) belongs to the special category of parafiscal taxes whose purpose is to benefit the payers of the special tax, by definition an earmarked tax. One of its original purposes was to finance investments in air quality surveillance systems. However, its creation was also inspired by the French water pollution charges which are levied upon industrial water users and then refunded in the form of abatement subsidies.

Initially introduced in 1985 for $\mathrm{SO}_{2}$ emissions, the government order on the TPPA was extended in 1990 to include also emissions of $\mathrm{NO}_{\mathrm{x}}{ }^{7}$ and hydrochloric acid ( $\left.\mathrm{HCl}\right)$, and in 1995 to include volatile organic compounds (VOC). ${ }^{8}$ The tax was imposed from 1990 on any entity that fulfills either of two criteria: a maximum combustion capacity equal to or exceeding 20 MW or annual emissions of more than 150 tonnes of either $\mathrm{SO}_{2}, \mathrm{NO}_{\mathrm{x}}, \mathrm{HCl}$, or $\mathrm{VOC}$.

In 1990, the tax targeting $\mathrm{SO}_{2}, \mathrm{NO}_{\mathrm{x}}$ and $\mathrm{HCl}$ emissions was put at a rate of 150FF/tonne (EUR23/tonne.) It was increased in 1995 to 180FF/tonne (EUR28/tonne) for all pollutants (including VOC), and in 1998 to 250FF/tonne (EUR38/tonne) for $\mathrm{NO}_{\mathrm{x}}$ and VOC only. If the total tax due was less than 1,000FF (EUR150) for a unit, no tax was levied. In 1997, this made for a total of 1,454 tax payers. Note that the system targets emissions from fixed sources only and that emissions originating from transportation are not subject to the $\operatorname{tax}^{9}$

The tax was administered by the French Agency for Environment and Energy Management (ADEME) $)^{10}$, and the regulation was based on self-reporting of emissions from the previous year. ADEME reports a high level of enforcement: over $90 \%$ of taxes due were actually paid. For emissions reporting purposes, firms could choose between real emissions monitoring on the one hand, either by installing equipment or paying an outside consultant to monitor emissions, and on the other hand use emission coefficients that are based on fuel input use and predetermined by the regulator. This kind of approximation of emissions works well for $\mathrm{SO}_{2}$ emissions, but does not proxy as well $\mathrm{NO}_{\mathrm{x}}$ emissions, since they originate from the combustion process and depend on operational factors, such as combustion temperature, oxygen intake etc. Based on the monitoring features of the regulation we would thus hypothesize that the air pollution tax had more of an incentives effect on $\mathrm{SO}_{2}$ emissions than on $\mathrm{NO}_{\mathrm{x}}$ emissions. 
The revenue from the TPPA was earmarked for subsidies (i.e. the revenue of the tax was redistributed to the polluters through subsidies) to abatement or for preparatory technical studies (corresponding to $75 \%$ of the tax revenues), with the rest aimed at investment in air quality surveillance systems. Subsidies were granted as a percentage of the capital cost of emission reductions according to the innovative character of the investment: $15 \%$ for standard technologies, 25\% for innovative technologies and 35\% for very innovative technologies. There was no explicit encouragement of one abatement technology over the other, apart from the fact that the percentage subsidy increased with the innovative character of the proposed technology. There was also an additional 10\% subsidy for small and medium sized companies.

Examples of technologies that were subsidized for abatement of $\mathrm{SO}_{2}$ emissions include the injection of alcaline chemicals, combustion on sulfur-removing fluidized beds, and wet and dry flue gas desulfurization. As regards $\mathrm{NO}_{\mathrm{x}}$ abatement, the regulation subsidized technologies such as exhaust gas recirculation and low $\mathrm{NO}_{\mathrm{x}}$ burners, selective non-catalyst reduction and selective catalyst reduction. Just as for the $\mathrm{SO}_{2}$ emissions abatement techniques listed above, these are techniques with quite a varying degree of effectiveness, ranging from $20-95 \%$.

As subsidies were calculated on the basis of the capital cost of investment, however, this may have created a bias towards end-of-pipe technologies, for which the investment costs are easier to quantify than clean technologies that often include management reorganization and possibly higher variable costs. In our sample, $80 \%$ of the subsidized equipment was endof-pipe technologies and almost all the plants received a subsidy representing $15 \%$ of the overall investment. For that reason, the subsidy rate can be considered as pre-determined for the plant and will be modelled as exogeneous to the firm in the empirical analysis.

An end-of-pipe equipment leads to a reduction of polluting emissions released into the atmosphere without involving any change in the combustion process (contrary to cleantechnology equipment). Even if an end-of-pipe equipment normally targets emissions of a particular pollutant, in some cases emissions from other pollutants can also be abated. This is the case in particular for plants emitting $\mathrm{NO}_{\mathrm{x}}$ and $\mathrm{SO}_{2}$. We will take this feature into account in the empirical model by allowing the abatement equipment to have an impact on both $\mathrm{NO}_{\mathrm{x}}$ and $\mathrm{SO}_{2}$ emissions.

It is important to note that virtually all subsidy requests were granted, so the decision to invest in abatement equipment is equivalent to receiving a subsidy. This is also crucial 
information when one wishes to model a plant's optimization problem as it implies that any plant willing to invest knows that she will get the subsidy with probability one.

In the year 2000, the TPPA was replaced by a general pollution $\operatorname{tax}^{11}$ levied by the customs authorities and no longer administered by ADEME, who nevertheless continues to handle requests for abatement subsidies paid out of the general government budget. Our analysis encompasses the period when the TPPA was an integrated earmarked tax system. Given that the tax rate in the French regulation seems to have been lower than the estimated interval of marginal costs of abatement, at least for $\mathrm{SO}_{2}$ emissions (Riedinger and Hauvuy, $2003)^{12}$, the expected incentives effect of the tax on its own would be zero. This is why it is important to analyze the entire system, including the effect of the subsidies

towards abatement.

\section{THEORETICAL MODEL}

The objective of the paper is to measure the effect of the tax and subsidy on emissions; in this section we develop a theoretical model that suggests the direction of the impact on emissions of the tax and subsidy and the factors that explain their effect.

In a general model, Fullerton and Wolverton (2000) and Fullerton and Mohr (2003) have shown that a subsidy to abatement increases emissions by lowering the cost of the polluting input, when there are no pigouvian taxes. ${ }^{13}$ The regulation we study here comprises an emission tax combined with an abatement subsidy so we develop a model that takes into account the existence of an emission tax. The contribution of the model presented here is that it allows the regulator to use a pigouvian tax and that it includes a measure of the effectiveness of abatement. We then show that similarly to the results in Fullerton and Wolverton (2000) and Fullerton and Mohr (2003), abatement subsidies can lead to increased emissions.

Consider a plant using a polluting input in its production process (the polluting input will be energy from fossil fuel in the subsequent empirical analysis). To simplify the analysis, assume the plant produces a single output $q(e)$ from a unit of energy input, $e$. The production function $q(e)$ is increasing and concave in energy use: $q_{e} \succ 0$ and $q_{e e} \prec 0$. The plant is assumed to take the unit output price $p$ as given. The firm's costs are a function of energy input and abatement, $a$, and denoted by: $I(a)(1-s)+w e$. The unit cost of energy is $w$ and we 
postulate that the investment cost of abatement is an increasing convex function of abatement $a: I_{a} \succ 0$ and $I_{a a} \geq 0$. Any plant which decides to invest knows, with probability one, that she will receive a subsidy (s) that is given as a fixed percentage of the capital investment cost. If there is no abatement, emissions are assumed to equal the dirty energy input, and any abatement lowers the emission coefficient towards zero. Emissions are thus written: $z=e \gamma(a)$, where $\gamma(a) \in] 0,1]$. Abatement, though effective at first, has decreasing returns to scale: $\gamma_{a} \prec 0, \gamma_{a a} \geq 0$.

The regulator uses two instruments to control pollution: the subsidy for investment in abatement equipment, set as a fixed percentage of the capital investment cost, and an emission tax $t$ (fixed rate per unit of emissions). The firm's problem is thus:

$$
\max _{e, a} \Pi=p q(e)-I(a)(1-s)-w e-t \gamma(a) e \text {. Optimal energy use } e^{*} \text { and abatement } a^{*} \text { are }
$$

determined by the following first-order conditions:

$$
\begin{aligned}
& p \frac{\partial q\left(e^{*}\right)}{\partial e}-w-t \gamma\left(a^{*}\right)=0 \\
& -\frac{\partial I\left(a^{*}\right)}{\partial a}(1-s)-t e^{*} \frac{\partial \gamma\left(a^{*}\right)}{\partial a}=0 .
\end{aligned}
$$

We thus have two simultaneous equations of two endogenous variables - energy use $e$ and abatement $a$ - and two exogenous policy instruments: the emission tax $t$ and the subsidy $s$. Define $D=p \frac{\partial^{2} q}{\partial e^{2}}\left[-\frac{\partial^{2} I}{\partial a^{2}}(1-s)-t e \frac{\partial^{2} \gamma}{\partial a^{2}}\right]-t^{2}\left(\frac{\partial \gamma}{\partial a}\right)^{2}$; this is a second order condition that has to be positive for a local maximum (See Appendix). ${ }^{14}$

In addition, two conditions are useful for determining the impact of the tax and the subsidy on emissions:

$$
\frac{d}{d a}\left[\gamma \frac{\partial I}{\partial a}\right] \succ 0
$$

Condition [3] says that abatement costs have to be sufficiently convex.

$$
-p \frac{\partial^{2} q}{\partial e^{2}} \succ \frac{t \gamma}{e} .
$$

Condition [4] says that the secondary productivity effects from energy use are larger than the average emissions tax payment per unit of energy in relation to total energy use.

The comparative statics for abatement and energy use are (see Appendix): 


$$
\begin{aligned}
& \frac{\partial a}{\partial s}=-\frac{p \frac{\partial^{2} q}{\partial e^{2}} \frac{\partial I}{\partial a}}{D} \succ 0 \\
& \frac{\partial e}{\partial s}=-\frac{t \frac{\partial \gamma}{\partial a} \frac{\partial I}{\partial a}}{D} \succ 0 \\
& \frac{\partial a}{\partial t}=\frac{\gamma t \frac{\partial \gamma}{\partial a}+p \frac{\partial^{2} q}{\partial e^{2}} e \frac{\partial \gamma}{\partial a}}{D} \succ 0 \\
& \frac{\partial \mathrm{e}}{\partial \mathrm{t}}=\frac{\gamma\left[-\frac{\partial^{2} I}{\partial a^{2}}(1-s)-t e \frac{\partial^{2} \gamma}{\partial a^{2}}\right]+t e\left(\frac{\partial \gamma}{\partial a}\right)^{2}}{D} \prec 0 \quad \text { if and only if [4] }
\end{aligned}
$$

The signs of the effect of the abatement subsidy are as expected. The subsidy increases abatement, and its indirect effect is to enable the firm to use more energy, all else equal. The effect of the tax on abatement and energy use is ambiguous. The emission tax has a positive effect on abatement if and only if the secondary effect of energy productivity exceeds the average emission tax per unit of energy in relation to total energy use. Intuitively, it is only when the firm's loss in the marginal productivity from reducing its energy use is high enough to exceed the cost of polluting energy use that the firm will prefer to invest in abatement rather than simply reducing the level of energy use. The sign of the tax's effect on energy use essentially depends on the curvature of the abatement investment function compared to the curvature of the technical abatement efficiency function $(\gamma(a))$. A sufficient condition for energy use to decrease in the emission tax is that abatement costs are sufficiently convex in the sense of condition [3].

Given that emissions, $z$, equal $e \gamma(a)$, the effect on emissions can now be derived as:

$$
\begin{aligned}
& \frac{\partial z}{\partial t}=\frac{\partial e}{\partial t} \gamma(a)+e \frac{\partial \gamma}{\partial a} \frac{\partial a}{\partial t} \prec 0 \text { if and only if }-\frac{\frac{\partial e}{\partial t}}{e} \succ \frac{\frac{\partial \gamma}{\partial a} \frac{\partial a}{\partial t}}{\gamma} ; \\
& \frac{\partial z}{\partial s}=\frac{\partial e}{\partial s} \gamma(a)+e \frac{\partial \gamma}{\partial a} \frac{\partial a}{\partial s} \prec 0 \text { if and only if } \frac{\frac{\partial e}{\partial s}}{e} \prec-\frac{\frac{\partial \gamma}{\partial a} \frac{\partial a}{\partial s}}{\gamma} .
\end{aligned}
$$

Note first that in this model where the externality arises from the use of polluting energy and where an abatement activity exists that can reduce the externality, the effect on emissions of both the tax and the subsidy are ambiguous (as shown in Baumol and Oates, 1988). A standard assumption on the convexity of the cost function (condition [3]) implies that the firm's energy use decreases with the tax rate. Normally, if abatement increases in the tax rate, then emissions will also decrease in the tax rate. There could be cases, though, where 
condition [4] does not hold and the impact of the tax rate on abatement is negative, i.e., the firm may invest less in abatement with a higher tax rate than in the optimal combination to reduce emissions through reduced energy use and abatement. This would be the case when a firm with low marginal productivity of energy use prefers to reduce energy use rather than invest in abatement. This negative effect on abatement then has to be outweighed by the direct negative impact of the tax on energy use. Sufficient conditions for emissions to decrease in the tax rate are [3] and [4]. The impact of the abatement subsidy on total emissions is ambiguous a priori, and whether it reduces overall emissions has to be tested empirically. It depends on whether the input-use increasing effect of a subsidy outweighs the pollution-

reducing effect from investment in abatement. If $\frac{\frac{\partial e}{\partial s}}{e} \succ-\frac{\frac{\partial \gamma}{\partial a} \frac{\partial a}{\partial s}}{\gamma}$, i.e., if the percentage increase in input use exceeds the percentage decrease in the pollution coefficient due to the subsidy, then the abatement subsidy increases total emissions of the plant. This is another example of the general analysis in Fullerton and Wolverton (2000), in which a subsidy to abatement may increase emissions by lowering the cost of the polluting input. The theoretical model has evaluated the separate effects of an emission tax and an abatement subsidy. Since the model does not link the size of the tax to the size of the subsidy, it does not make any prediction about the impact on emissions of an earmarked tax-subsidy combination. The empirical analysis will allow us to compare the relative size of the two effects.

\section{EMPIRICAL ANALYSIS}

Our objective here is to measure the relative effect on emissions of the tax and the abatement subsidy. The empirical analysis is limited to the two major air pollutants, $\mathrm{NO}_{\mathrm{x}}$ and $\mathrm{SO}_{2}$, and three industrial sectors (iron and steel, coke, and chemistry). These three sectors are some of the main contributors to both $\mathrm{NO}_{\mathrm{x}}$ and $\mathrm{SO}_{2}$ emissions and are sectors in which a significant number of subsidies has been granted (which is a necessary condition for identification of the impact of the subsidy on emissions).

Specification of the Model and Estimation Procedure

For a given pollutant $\left(\mathrm{NO}_{\mathrm{x}}\right.$ or $\left.\mathrm{SO}_{2}\right)$, the model describing emissions of plant $i$ at time $t$ is specified as follows: 
$z_{i t}=X_{i t}^{\prime} \beta+\alpha t_{t}+\gamma s_{i t}+\lambda_{t}+\mu_{i}+\varepsilon_{i t}, i=1, \ldots, I t=1, \ldots, T$.

$I$ and $T$ are the total number of plants and the total number of time periods respectively. We assume that polluting emissions of plant $i$ in year $t\left(z_{i t}\right)$ depend on plant characteristics $\left(X_{i t}\right)$ (such as input and output prices, production level, etc.), the tax rate for this particular pollutant $\left(t_{t}\right)$ (which is the same across all industrial sectors but varies over time), and whether the plant uses or not an abatement technology subsidized by ADEME, $s_{i t} . s_{i t}$ is a category variable which takes the value of 1 in time period $t$ and after if plant $i$ has received a subsidy by ADEME for investing in abatement technology at time $t$, and 0 otherwise. The panel form of the data calls for the specification of a plant-specific effect $\left(\mu_{i}\right)$ to control for timeinvariant unobservable plant characteristics. To account for factors that may have affected all plants at the same time, we include time dummies, $\lambda_{t} . \alpha, \gamma, \beta$, and $\lambda_{t}$ are parameters to be estimated. $\varepsilon_{i t}$ is the usual error term with assumed mean 0 and constant variance.

To account for the observed fact that plants emit both types of pollutants and that an end-of-pipe equipment can lower both types of emissions, we estimate the system combining both emissions equations:

$z_{i t}^{N}=X_{i t}^{\prime} \beta^{N}+\alpha^{N} t_{t}^{N}+\gamma^{N} s_{i t}+\lambda_{t}^{N}+\mu_{i}^{N}+\varepsilon_{i t}^{N}$
$z_{i t}^{S}=X_{i t}^{\prime} \beta^{S}+\alpha^{S} t_{t}^{S}+\gamma^{S} s_{i t}+\lambda_{t}^{S}+\mu_{i}^{S}+\varepsilon_{i t}^{S}$

where $N$ and $S$ respectively indicates emissions of $\mathrm{NO}_{\mathrm{x}}$ and $\mathrm{SO}_{2}$.

The decision of a plant to use a subsidized abatement technology $\left(s_{i t}\right)$ is likely to be endogenous in the model as some observable and unobservable plant characteristics which determine the decision of a plant might also have an impact on total emissions (e.g. the manager's concern about environmental issues). To overcome this possible selection bias problem, the common approach is to model the decision of the plant to use the subsidized abatement equipment. We only observe the decision of the plant to invest in the abatement equipment in period $t$ but we assume from now on that a plant which invests in a new abatement equipment in period $\bar{t}$ will be using it from period $\bar{t}$ onwards, and we will have $s_{i t}=1 \forall t \geq \bar{t}$. We assume that a plant is willing to invest in period $t$ if the expected net benefit of this decision is positive in $t$ but also in all subsequent years. The decision model at time $t$ is thus written:

$s_{i t}^{*}=Z_{i t}^{\prime} \nu+v_{i t} \geq 0$

where $s_{i t}^{*}$ represents the expected net benefit from using an abatement equipment. $Z_{i t}$ are plant-specific characteristics which determine the firm's decision and which may have some 
elements in common with $X$. The latent variable, $s^{*}$, is not observed, only the outcome of this model (i.e. the decision to install an abatement equipment) is known to the econometrician. The common approach is to estimate the probability that the plant uses an abatement equipment using the following Probit model:

$s_{i t}=F\left(Z_{i t}^{\prime} v\right)+\varpi_{i t}$

where $s_{i t}$ takes the value of 1 [resp. 0] if the expected net benefit $\left(s_{i t}^{*}\right)$ is positive [resp. negative]. $F$ is the cumulative distribution of the $v_{i t}$ error terms, assumed standard normal.

The above model is estimated using a two-stage estimation procedure. In the first step we apply maximum-likelihood (ML) to estimate the probability that a plant uses an abatement equipment (equation [8]). ML provides consistent estimates of the $v$ parameters which are used to compute the predicted probability, $\hat{s}_{i t}=F\left(Z_{i t}^{\prime} \hat{v}\right)$. The estimated probability, $\hat{s}_{i t}$, is then used as an explanatory variable in the two emissions equations to correct for possible endogeneity of the variable s, along the lines of Lee and Trost (1978) (see also Khanna and Damon 1999, for an application of the same two-stage procedure). Another endogeneity bias could arise from the correlation between the unobservable plant specific-effects $\left(\mu_{i}\right)$ and some of the observables in the model. To overcome this possible endogeneity problem, all variables in both models are deviated from their time mean (the plant-specific effect, and hence the source of the endogeneity problem, is eliminated by this transformation). The transformed emissions equations for $\mathrm{NO}_{\mathrm{x}}$ and $\mathrm{SO}_{2}$ are then estimated simultaneously, using seemingly unrelated regression (SUR) methods to control for possible correlation between the two error terms, $\varepsilon_{i t}^{N}$ and $\varepsilon_{i t}^{S}$. The application of the Generalized Least Squares (GLS) method to this SUR model provides consistent and efficient estimates of the emissions equations parameters. The choice of the exogenous variables to be included in the two equations (the $X$ and $Z$ vectors) is discussed in the following section.

\section{Data and Estimation Results}

Our data set is an unbalanced panel from 1990 to 1998 of 226 French plants belonging to three industrial sectors (iron and steel, coke, and chemistry), with a total of 1,386 observations. The selected sectors are some of the main contributors to $\mathrm{NO}_{\mathrm{x}}$ and $\mathrm{SO}_{2}$ emissions in France (see ADEME).

For each plant, data from ADEME contain: its geographical location, industry sector, the total amount of emissions as well as taxes paid to the agency, and whether an abatement subsidy had been granted. A search for plant ID numbers allowed us to match the existing 
plant-level data with data from the energy survey made by the French Ministry of Industry: the plant's consumption and purchases of ten different types of energy (among them electricity, coke, petroleum, gas) as well as the average price of each energy source. We compute total energy purchases and average annual weighted price of energy for each plant. Additional information from the French Ministry of Industry has also been incorporated into the data set: total labor cost (i.e. total amount of wages), and value added, the latter being known at the firm-level only. For this variable, we have attributed the characteristic of the main company to its subsidiary plants.

All monetary amounts have been transformed into FF1990 and then into euros to facilitate a comparison with USD. ${ }^{15}$ Prices were deflated with the price index of sales of industrial products (source: INSEE, the French National Statistics Institute).

Of the 226 plants recorded in our database, 62 were granted a subsidy in the 1990-98 period. The number of plants and the allocation of subsidies across the three sectors are reported in Table 1.

\section{[insert Table 1 here]}

We observe (see Table 2) that the plants which decided to invest and apply for an abatement subsidy on average have higher emissions of $\mathrm{NO}_{\mathrm{x}}$ and $\mathrm{SO}_{2}$ than non-investors. Investing plants are furthermore characterized by high input expenses for energy and labour in general, and belong to firms producing items of high value added. These variables which relate to plant size and activity seem good candidates to discriminate between investors and non-investors and will thus be included as determinants of the plant's decision to invest in abatement. Total input expenses (for labour and energy) are preferred to input prices as they allow to control for the size of the plant. Note that the total value of energy purchases will be instrumented as it might be endogenous (from the theoretical model, energy consumption is shown to be influenced by the investment decision). ${ }^{16}$ From the basic descriptive statistics, we expect that a plant with greater input expenses and a higher amount of emission tax payments will be more likely to invest in abatement. The ratio of self-financing capacity over value added measures the ability of the plant to self-finance its investments. This is particularly important here as only part of the total investment is covered by the subsidy. A higher ability to self-finance investment should increase the probability of the plant to invest in abatement technology. Furthermore, in order to account for regulatory pressure originating from the regulator observing exceedance of health-based air quality norms, we include in the model 
data on exceedance of air quality levels from IFEN, the French National Institute of the Environment. Since the data only exist for four years of the estimation period (1992, 1993, 1994, 1995) and do not exhibit much variation we use the average over these four years. The available data is regional and captures the average number of measurement points with at least one exceedance of an hour of the air quality standards for $\mathrm{SO}_{2}\left(350\right.$ microgrammes $/ \mathrm{m}^{3}$ ) and $\mathrm{NO}_{\mathrm{x}}\left(200\right.$ microgrammes $\left./ \mathrm{m}^{3}\right)$ respectively. We expect that the regulatory pressure on the plant would be greater in those regions where air quality standards are exceeded.

\section{[insert Table 2 here]}

Each of the two emissions equations is specified as a function of the predicted probability of investing in abatement technology, the tax rate, and plant characteristics. From the FOC derived from the maximization program of the plant (equations [1] and [2]), plant characteristics should include input and output prices. However, information on input and output prices was very limited in our data and only the price of energy is available. To control for heterogeneity across plants, we use as extra regressors value added, the ratio of selffinancing capacity over value added, and total wages. ${ }^{17}$ We also include year dummies to account for time-specific effects that would have affected all industrial sectors at the same

time. ${ }^{18}$ A specific time effect is included for the sector of coke which has been in decline from the mid-nineties when an agreement was signed between industry and the government that the coke sector should phase out its activities by 2007.

The estimation results for the Probit model are displayed in Table 3. The overall fit of the model is satisfactory: the Likelihood Ratio test shows the overall significance of the parameters and the model predicts correctly $82 \%$ of the outcomes. Wald tests show that the total amount of taxes has an impact on the decision to invest which varies across sectors (pvalue corresponding to the null of equal parameters is 0.0559). Overall, these results show that plants of bigger size (i.e. plants with higher emissions and higher expenses in labour and energy) are more likely to use subsidized abatement equipment. Furthermore, a plant with a higher self-financing capacity (per unit of value added) is found more likely to adopt an abatement equipment, probably because only a small fraction of the investment is covered by the subsidy. Sectoral dummy variables indicate that plants from the sectors of coke and chemistry have a higher probability to invest in an abatement technology than plants from the iron and steel industry, all other things equal. The variables measuring exceedance of air 
quality standards in the region where the plant is located have positive signs, which may be because authorities put more pressure on the plants in those regions to reduce emissions.

[insert Table 3 here]

The emissions equations for $\mathrm{NO}_{\mathrm{x}}$ and $\mathrm{SO}_{2}$, in which all variables have been deviated from their time means, are estimated simultaneously using GLS (see Table 4). Different specifications have been tried (log-log, log-lin, lin-lin). Reported results correspond to the case of lin-lin emissions equations, which provided the best fit (as measured by R-square in the two equations, and the Akaike Information criterion). The overall fit is measured by the Rsquare, which is equal to 0.11 [resp. 0.16] for the $\mathrm{NO}_{\mathrm{x}}$ [resp. $\mathrm{SO}_{2}$ ] equation. The lack of information on input and output prices (except for the price of energy) probably explains the relatively low fit of the models. Wald tests were run to check for equal effects of the different variables across sectors. These tests prove that sector-specific parameters should be specified for the tax and the probability to adopt an abatement equipment (see Table 4). Finally, the Breusch-Pagan (1980) chi-square statistic (a Lagrange Multiplier statistic) shows that both equations cannot be assumed independent.

\section{[insert Table 4 here]}

Even if the overall fit is low, the parameters of interest (i.e. those associated with the tax and the subsidy indicator) are significant for all three sectors. The pollution tax is found to negatively affect both $\mathrm{NO}_{\mathrm{x}}$ and $\mathrm{SO}_{2}$ emissions, the marginal impact of the tax being stronger in the case of $\mathrm{SO}_{2}$ (from -77 to -37 tonnes of $\mathrm{SO}_{2}$ for a marginal increase of the tax rate for this pollutant, and from -30 to -20 tonnes in the case of $\mathrm{NO}_{\mathrm{x}}$ ). We attribute this to the French regulation's statutes for monitoring. Under the French regulation, firms could choose between using direct emissions monitoring or using emission factors to calculate emissions from fuel consumption data. For $\mathrm{SO}_{2}$ emissions, the use of emission factors constitutes a good proxy for real emissions. For $\mathrm{NO}_{\mathrm{x}}$ emissions, on the contrary, accurate real emissions monitoring is more important since emissions vary strongly with fine-tuning of plant operations.

The parameters associated with the subsidy are all positive and highly significant. It thus seems that in this specific case, the input-use increasing effect of an abatement subsidy exceeded its direct pollution-reducing effect. For this to happen, the marginal technical abatement efficiency has to be quite small. In our sample, this seems to be the case, since 
primary emission reduction technologies were predominant. The Wald test rejects the null of equal effects across sectors, which emphasizes that the analysis has to allow for sectorspecific effects of the policy.

The time dummy variables should control for any autonomous technical improvement in the emission factors. They are significant only for $\mathrm{NO}_{\mathrm{x}}$ emissions, for which there is a decreasing trend. For the coke sector we find in addition that emissions tended to decrease less than for the sectors of iron and steel, and chemistry. Most likely it reflects the fact that this sector should have less incentives for emissions abatement since its activities should be phased out anyway by 2007.

Energy price is not significant in any of the models, contrary to what would have been expected from the theoretical model. We use calculated average prices, though, which may not be a good proxy for the energy price actually faced by the firm. Among the other variables included in the model to control for plant heterogeneity, the variable measuring the plant's self-financing capacity as well as the amount of total wages are found significant.

The above estimation results can be used to derive the elasticity of emissions with respect to the tax as well as the overall effect on emissions of the tax and the subsidy, for each sector and each pollutant (see Table 5). In each case, the elasticity is computed at the sample mean. The overall estimated effect of the tax is computed, for each sector and each pollutant, as the product of the corresponding estimated coefficient ( $\hat{\alpha}$ in model [6]) with the average emission tax over the period. The overall estimated effect of the subsidy is directly obtained from the estimated parameter $\hat{\gamma}$ (see model [6]). The 95\% confidence interval is reported in all cases. Estimated emission tax elasticities vary from -2.67 to -0.59 in the case of $\mathrm{NO}_{\mathrm{x}}$, and from -2.26 to -0.21 in the case of $\mathrm{SO}_{2}$. Plants in the coke industry were the least responsive to the tax. Estimated effects show that generally the (positive) effect of the subsidies outweighed the (negative) effect of the tax. Hence our empirical analysis shows that the combined tax/subsidy system in general increased polluting emissions in the three sectors considered. We believe that this result is explained by the low level of the French air pollution tax compared to the levels of abatement subsidies as well as a low effectiveness of the subsidized technologies, which led the input-use increasing effect of an abatement subsidy to dominate the pollution-reducing effect of the subsidy.

[insert Table 5 here] 
The objective of the paper was to make an ex post evaluation of the effectiveness of one form of environmental taxation, an earmarked air pollution tax. We gathered original data on the French tax on air pollution and emissions of $\mathrm{SO}_{2}$ and $\mathrm{NO}_{\mathrm{x}}$. The revenues of the French tax on air pollution were refunded to the polluters through subsidies for investment in pollution abatement technology.

A theoretical model was derived to describe the behaviour of a representative plant under the French system of taxes and subsidies. From this theoretical framework, we built a system of equations to estimate the impact of the combined tax/subsidy system on the level of emissions, while controlling for endogeneity of the plant decision to invest in air pollution abatement. We used a two-stage estimation procedure on a plant-level database on emissions, firm characteristics, taxes paid and subsidies received.

The results indicate that the overall effectiveness of a tax/subsidy policy like the French air pollution tax system during the nineties can be questioned. For all three sectors in our sample, the tax had a significant negative impact on emissions, but the reduction in emissions was larger for $\mathrm{SO}_{2}$ than for $\mathrm{NO}_{\mathrm{x}}$ emissions. We attribute this difference in the impact to the French regulation's monitoring procedures for emissions. All else equal, the higher the total amount of pollution taxes paid, the higher the probability that the plant applied for an abatement subsidy. The effect of the combined subsidy, however, was found to increase total emissions significantly and to an extent that generally dwarfed the negative impact of the tax. We believe that this result is explained by the low level of the French air pollution tax compared to the levels of abatement subsidies as well as a low effectiveness of the subsidized technologies, which led the input-use increasing effect of an abatement subsidy to dominate the pollution-reducing effect of the subsidy.

In a general policy context this does not mean that earmarking of environmental tax revenues should be abandoned as a means of overcoming industry resistance to taxes. The efficiency loss created by the refunding of revenues in a non lump sum manner should be carefully weighted against the likelihood of getting a pigouvian tax implemented. It is quite likely that earmarking of tax revenues is necessary in order to overcome political obstacles towards taxes. Fredriksson (1997b) develops a political economy model with industry and environmental lobby groups to explain the simultaneous use of emission taxes and abatement subsidies. Albeit in a very different political economy model than the model used here, Fredriksson (1997a) reaches a similar conclusion that pollution abatement subsidies can increase pollution if the output-increasing effect of the subsidy exceeds its pollution-reducing 
effect. In particular, he derives more subtle effects of the abatement subsidy on the pollution tax rate due to lobby interactions with the government. Here, our interest is in the effect of the tax and abatement subsidy on emissions, rather than explaining why the policy was instituted in the first place. We note, though, that the low effectiveness of the French tax/subsidy on air pollution probably was due to the relatively low tax rate compared to the level of the abatement subsidies. Nevertheless, we would argue that there are also fundamental institutional features of the regulation that would need to be addressed and borne in mind for the design of any environmental tax scheme where revenues are refunded to polluters.

In the first place, monitoring of real emissions is a necessary prerequisite to keep the link between the tax base and emissions, in particular as regards emissions of $\mathrm{NO}_{\mathrm{x}}$. It is instructive, in this regard, to compare the French tax on $\mathrm{NO}_{\mathrm{x}}$ with the Swedish refunded emission payment on $\mathrm{NO}_{\mathrm{x}}$ from industrial sources. The refunding of the revenue of the Swedish $\mathrm{NO}_{\mathrm{x}}$ charge was motivated in part by the requirement to install costly monitoring equipment, for the reason that it is not simply the installation of abatement equipment that matters but its fine tuning and continued adjustment to the production process (as $\mathrm{NO}_{\mathrm{x}}$ emissions depend not only on the fuel input but also on process factors such as the temperature and oxygen content of the combustion chamber). Precise monitoring equipment encourages the use and fine tuning of the production process to minimize emissions. The other important design feature concerns the mechanism by which the tax revenues are refunded to the tax-payers. Under the French regulation, tax revenues were used to subsidize abatement investments and the selection of projects was made following an administrative procedure. Such a rule has at least three drawbacks. First, firms may receive subsidies for investments that they would have undertaken anyway. This would be contrary to what is suggested by the theoretical model, though, and we cannot test whether the earmarked tax system has provided incentives to plants to invest in pollution abatement technology since we do not have any data before the tax/subsidy system was put in place. We would venture that this drawback is of less significance in the French context, for which the earmarked tax was introduced to give additional incentives to firms to invest in abatement technology. Second, there is no built-in check on the ex post efficiency or proper use of subsidized abatement equipment. By comparison, the revenues from the Swedish $\mathrm{NO}_{\mathrm{x}}$ charge were refunded in relation to the amount of energy produced by the specific plant. An automatic refunding rule like that of the Swedish $\mathrm{NO}_{\mathrm{x}}$ charge provides continuous incentives to firms to reduce emissions and become more efficient in terms of emissions per energy unit. Such a refunding rule is feasible to implement in the case of emissions deriving from energy use (like $\mathrm{SO}_{2}$ and 
$\mathrm{NO}_{\mathrm{x}}$ emissions), since a common measurement unit exists across different industrial sectors. Third, the calculation of subsidies as a percentage of capital costs seems likely to have favored large-size plants and to have created a bias towards end-of-pipe measures rather than reorganization of production processes that recycles or substitutes polluting inputs. In conclusion, environmental taxes have a real potential to reduce emissions in an efficient manner, but as with taxes in general, the institutional design of the tax system is crucial. 
Let $(1-s)=u$. Differentiating the two first order conditions in [1] and [2] and putting into matrix form gives:

$$
\left(\begin{array}{cc}
p \frac{\partial^{2} q}{\partial e^{2}} & -t \frac{\partial \gamma}{\partial a} \\
-t \frac{\partial \gamma}{\partial a} & -\frac{\partial^{2} I}{\partial a^{2}} u-t e \frac{\partial^{2} \gamma}{\partial a^{2}}
\end{array}\right)\left[\begin{array}{l}
d e \\
d a
\end{array}\right]=\left[\begin{array}{l}
\gamma d t \\
\frac{\partial I}{\partial a} d u+e \frac{\partial \gamma}{\partial a} d t
\end{array}\right] .
$$

The determinant of the left-hand matrix is denoted by $D$,

$D=p \frac{\partial^{2} q}{\partial e^{2}}\left[-\frac{\partial^{2} I}{\partial a^{2}} u-t e \frac{\partial^{2} \gamma}{\partial a^{2}}\right]-t^{2}\left(\frac{\partial \gamma}{\partial a}\right)^{2}$.

We will assume that it is positive, in order to have a maximum. The other second-order condition is fulfilled by the assumptions of the model: $p \frac{\partial^{2} q}{\partial e^{2}}-\frac{\partial^{2} I}{\partial a^{2}} u-t e \frac{\partial^{2} \gamma}{\partial a^{2}} \prec 0$.

By using Cramér's rule, we can solve for $d e$ and $d a$ :

$$
\begin{aligned}
& d e=\frac{\left(\begin{array}{cc}
\gamma d t & -t \frac{\partial \gamma}{\partial a} \\
\frac{\partial I}{\partial a} d u+e \frac{\partial \gamma}{\partial a} d t & -\frac{\partial^{2} I}{\partial a^{2}} u-t e \frac{\partial^{2} \gamma}{\partial a^{2}}
\end{array}\right)}{D}=\frac{\gamma d t\left[-\frac{\partial^{2} I}{\partial a^{2}} u-t e \frac{\partial^{2} \gamma}{\partial a^{2}}\right]+t \frac{\partial \gamma}{\partial a}\left[\frac{\partial I}{\partial a} d u+e \frac{\partial \gamma}{\partial a} d t\right]}{D} \\
& d a=\frac{\left(\begin{array}{cc}
p \frac{\partial^{2} q}{\partial e^{2}} & \gamma d t \\
-t \frac{\partial \gamma}{\partial a} & \frac{\partial I}{\partial a} d u+e \frac{\partial \gamma}{\partial a} d t
\end{array}\right)}{D}=\frac{p \frac{\partial^{2} q}{\partial e^{2}} \frac{\partial I}{\partial a} d u+p \frac{\partial^{2} q}{\partial e^{2}} e \frac{\partial \gamma}{\partial a} d t+t \frac{\partial \gamma}{\partial a} \gamma d t}{D} .
\end{aligned}
$$

The partial derivatives are derived by changing only one exogenous variable at the time, and using $\frac{\partial a}{\partial s}=-\frac{\partial a}{\partial u}$ and $\frac{\partial e}{\partial s}=-\frac{\partial e}{\partial u}$ : 


$$
\begin{aligned}
& \frac{\partial a}{\partial s}=-\frac{p \frac{\partial^{2} q}{\partial e^{2}} \frac{\partial I}{\partial a}}{D} \\
& \frac{\partial e}{\partial s}=-\frac{t \frac{\partial \gamma}{\partial a} \frac{\partial I}{\partial a}}{D} \\
& \frac{\partial a}{\partial t}=\frac{\gamma t \frac{\partial \gamma}{\partial a}+p \frac{\partial^{2} q}{\partial e^{2}} e \frac{\partial \gamma}{\partial a}}{D} \\
& \frac{\partial \mathrm{e}}{\partial \mathrm{t}}=\frac{\gamma\left[-\frac{\partial^{2} I}{\partial a^{2}}(1-s)-t e \frac{\partial^{2} \gamma}{\partial a^{2}}\right]+t e\left(\frac{\partial \gamma}{\partial a}\right)^{2}}{D} .
\end{aligned}
$$

By substitution from the FOC (equation [2]), te $\frac{\partial \gamma}{\partial a}=-\frac{\partial I}{\partial a} u$, and

$$
\frac{\partial e}{\partial t}=\frac{-t e \frac{\partial^{2} \gamma}{\partial a^{2}} \gamma+u\left[-\gamma \frac{\partial^{2} I}{\partial a^{2}}-\frac{\partial \gamma}{\partial a} \frac{\partial I}{\partial a}\right]}{D}=\frac{-t e \frac{\partial^{2} \gamma}{\partial a^{2}} \gamma-u \frac{d}{d a}\left(\gamma \frac{\partial I}{\partial a}\right)}{D}
$$




\section{References}

ADEME. 1990/95, 1995, 1996, 1997. Taxe parafiscale sur la pollution atmosphérique, Rapport d'Activité (The Tax on Air Pollution, Yearly Reports). Paris, France : Agence de l'Environnement et de la Maîtrise de l’Energie.

Baumol, W.J. and W.E. Oates. 1988. The Theory of Environmental Policy. Cambridge, UK: Cambridge University Press. 2nd edition.

Björner, T.B., and H.H. Jensen. 2002. "Energy Taxes, Voluntary Agreements and Investment Subsidies - A Micro-Panel Analysis of the Effect on Danish Industrial Companies’ Energy Demand.” Resource and Energy Economics 24 (3): 229-49.

Bös, D. 2000. “Earmarked Taxation: Welfare versus Political Support.” Journal of Public Economics 75 (3): 439-62.

Brett, C., and M. Keen. 2000. "Political Uncertainty and the Earmarking of Environmental Taxes.” Journal of Public Economics 75 (3): 315-40.

Breusch, T., and A. Pagan. 1980. “The LM Test and its Applications to Model Specification in Econometrics.” Review of Economic Studies 47: 239-54.

Bruvoll, A., and B.M. Larsen. 2004. “Greenhouse Gas Emissions in Norway - Do Carbon Taxes Work?” Energy Policy 32 (4): 493-505.

Buchanan, J.M., and G. Tullock. 1975. “Polluters’ Profits and Political Response: Direct Control Versus Taxes.” American Economic Review 65: 139-47.

Carlson, C., D. Burtraw, M. Cropper and K.L. Palmer. 2000. “Sulfur Dioxide Control by Electric Utilities: What are the Gains from Trade?” Journal of Political Economy 108 (6): 1292-1326.

CITEPA. 2002. Emissions dans l'Air en France (Airborne Emissions in France). Paris, France: Centre Interprofessionel Technique d’Etudes de la Pollution Atmosphérique.

Fischer, C. 2001. "Rebating Environmental Policy Revenues: Output-Based Allocations and Tradable Performance Standards.” RFF Discussion Paper 01-22, Washington, DC: Resources for the Future.

C. 2003. "Market Power and Output-Based Refunding of Environmental Policy Revenues." RFF Discussion Paper 03-27, Washington, DC: Resources for the Future. Fredriksson, P. 1997a. “The Political Economy of Pollution Taxes in a Small Open Economy.” Journal of Environmental Economics and Management 33: 44-58. 
Fredriksson, P. 1997b. “Environmental Policy Choice: Pollution Abatement Subsidies.” Resource and Energy Economics 20: 51-63.

Fullerton, D. and A. Wolverton. 2000. "Two Generalizations of a Deposit-Refund System.” American Economic Review 90 (2): 238-42.

Fullerton, D. and R.D. Mohr. 2003. "Suggested Subsidies are Sub-Optimal Unless Combined with an Output Tax.” Contributions to Economic Analysis and Policy 2 (1).

http://www.bepress.com/bejeap/contributions/vol2/iss1/art1.

Gersbach, H. and T. Requate. 2004. "Emission Taxes and Optimal Refunding Schemes.” Journal of Public Economics 88: 713-25.

Harrington, W., R.D. Morgenstern and P. Nelson. 2000. “On the Accuracy of Regulatory Cost Estimates.” Journal of Policy Analysis and Management 19 (2): 297-322.

Höglund, L. 2000. "Essays on Environmental Regulation with Applications to Sweden.” Ph.D. diss., Department of Economics, Göteborg University.

Joskow, P. L., R. Schmalensee and E. Bailey. 1998. “The Market for Sulfur Dioxide Emissions.” American Economic Review 88 (4): 669-85.

Kerr, S. and R. Newell. 2003. "Policy-Induced Technology Adoption: Evidence from the U.S. Lead Phasedown.” Journal of Industrial Economics 51 (3): 317-43.

Khanna, M. and L.A. Damon. 1999. “EPA’s Voluntary 33/50 Program: Impact on Toxic Releases and Economic Performance of Firms.” Journal of Environmental Economics and Management 37: 1-25.

Kohn, R. 1992. "When Subsidies for Pollution Abatement Increase Total Emissions.” Southern Economic Journal 59: 77-87.

Lee, L. and R.P. Trost. 1978. "Estimation of some limited dependent variable models with applications to housing demand.” Journal of Econometrics 8: 357-82.

Marsiliani, L. and T. Renström. 2000. “Time Inconsistency in Environmental Policy: Tax Earmarking as a Commitment Solution.” Economic Journal 110 (462): 123-38.

McKibbin, W.J. and P.J. Wilcoxen. 2002. “The Role of Economics in Climate Change Policy.” Journal of Economic Perspectives 16 (2): 107-29.

Millock, K. and C. Nauges. 2003. "The French Tax on Air Pollution: Some Preliminary Results on its Effectiveness.” FEEM Working Paper No. 44.2003, Milan, Italy: Fondazione ENI Enrico Mattei.

Pirttilä, J. 1999. “Earmarking of Environmental Taxes and Pareto-Efficient Taxation.” Finanzarchiv 56: 202-17. 
Riedinger, N. and E. Hauvuy. 2003. "Une estimation du coût de dépollution atmosphérique pour les entreprises françaises (An Estimation of the Cost of Reducing Air Pollution for French Industry).” Mimeo, Paris, France: Institut National de la Statistique et des Etudes Economiques.

Stavins, R. 1998. "What Can We Learn from the Great Policy Experiment? Lessons from the $\mathrm{SO}_{2}$ Allowance Trading.” Journal of Economic Perspectives 12 (3): 69-88.

Sterner, T. 2002. Policy Instruments for Environmental and Natural Resource Management. Washington, DC: Resources For the Future Press.

Sterner, T. and L. Höglund. 2000. “Output Based Refunding of Emissions Payments: Theory, Distribution of Costs, and International Experience.” RFF Discussion Paper 00-29, Washington, DC: Resources for the Future.

Wang, H. and M. Chen. 1999. "How the Chinese System of Charges and Subsidies Affects Pollution Control Efforts by China’s Top Industrial Polluters.” Policy Research Working Paper No. 2198, Washington, DC: World Bank.

Wang, H. and D. Wheeler. 1996. “Endogenous Enforcement and Effectiveness of China’s Pollution Levy System.” Policy Research Working Paper No. 1090, Washington, DC: World Bank. 


\section{Endnotes}

1. A system combining tax and subsidy exists also in China to control industrial pollution (Wang and Wheeler 1996).

2. Recent theoretical analyses investigate why earmarking of tax revenues in general can be a second-best solution for the regulator in settings with asymmetric information (Pirttilä 1999), time inconsistency (Marsiliani and Renström 2000), political lobbying (Bös 2000) or political uncertainty (Brett and Keen 2000).

3. Fischer (2003) also discusses some additional disadvantages with output-based allocation of environmental tax revenue: the difficulty to define output and the relevant sector coverage, and unexpected entry and exit effects following manipulation of eligibility for an output subsidy.

4. Interestingly, Harrington, Morgenstern and Nelson (2000) find that economic incentives actually outperformed the performance goal, whereas the costs per ton of emissions often were overestimated in the ex ante analysis.

5. Measured in $\mathrm{kg} \mathrm{NO}_{\mathrm{x}} / \mathrm{MWh}$ useful energy.

6. In a similar vein, Wang and Chen (1999) use econometric methods to evaluate the chargesubsidy system used in China, but only for water pollution. They also use data for only one year (1993) but lack data on the subsidies for abatement, and evaluate the impact of the regulation on polluters' abatement investment and operating costs.

7. The tax was levied on the sum of nitrogen oxide (NO), nitrogen dioxide $\left(\mathrm{NO}_{2}\right)$ and nitrous oxide $\left(\mathrm{N}_{2} \mathrm{O}\right)$, expressed in units of $\mathrm{NO}_{2}$.

8. The extension in 1995 also included small particulate matter, but the tax rate was set at zero for those emissions at that time.

9. In 2000, the transportation sector was responsible for 50\% [resp. 23\%] of total anthropogenic $\mathrm{NO}_{\mathrm{x}}$ [resp. $\mathrm{SO}_{2}$ ] emissions in France. Source: Centre Interprofessionnel Technique d'Etudes de la Pollution Atmosphérique (CITEPA 2002).

10. Agence de l'Environnement et de la Maîtrise de l'Energie.

11. La Taxe Générale sur les Activités Polluantes (TGAP).

12. Riedinger and Hauvuy (2003) find a $5 \%$ confidence interval for $\mathrm{SO}_{2}$ abatement costs of EUR 309-986 per ton. Abatement costs for $\mathrm{NO}_{\mathrm{x}}$ emissions are found to be zero but nonsignificant. 
13. In a different context, Kohn (1992) also shows that subsidies to pollution abatement may increase total emissions due to entry into the industry.

14. From now on, we simplify the notation by omitting the arguments of the functions.

15. We use the fixed exchange rate of $6.55957 \mathrm{FF} / \mathrm{euro}$.

16. Instruments are sectoral and year dummy variables, value added, and energy price.

17. Value added is used as a proxy for the production level, which is not observed in our data. Total wages are used instead of the average price of labour which was found to be unreliable. 18. The model was also estimated interacting the time dummies with industry dummies. None of these cross-effects were found significant. 
Tables

Table 1: Number of Plants and Subsidies Granted

\begin{tabular}{lcc}
\hline Sector & $\begin{array}{c}\text { Number of } \\
\text { plants }\end{array}$ & $\begin{array}{c}\text { Number of } \\
\text { subsidies }\end{array}$ \\
Iron and steel & 68 & 14 \\
Coke & 26 & 17 \\
Chemistry & 132 & 31 \\
Total & 226 & 62 \\
\hline
\end{tabular}


Table 2: Sample Statistics on Investors and Non-Investors

\begin{tabular}{llcccc}
\hline & & \multicolumn{3}{c}{ Investors } & \multicolumn{2}{c}{ Non-investors } \\
& Unit & Mean & (St Dev) & Mean & (St Dev) \\
$\mathrm{NO}_{\mathrm{x}}$ emissions & (tonne) & 868 & $(1,481)$ & 203 & $(654)$ \\
$\mathrm{SO}_{2}$ emissions & (tonne) & 3,918 & $(7,194)$ & 676 & $(2,493)$ \\
Value of energy purchases & (thousand euros) & 18.98 & $(43.84)$ & 8.45 & $(14.21)$ \\
Energy price & (thousand euros/TPE $\left.)^{\mathrm{a}}\right)$ & 0.24 & $(0.16)$ & 0.19 & $(0.07)$ \\
Wages & (million euros) & 22.39 & $(27.96)$ & 12.94 & $(17.88)$ \\
Value Added & (million euros) & 0.69 & $(1.19)$ & 0.23 & $(0.39)$ \\
Self-financing capacity/value added & - & 0.14 & $(1.00)$ & 0.12 & $(0.60)$ \\
Number of plants & & & 62 & & \\
\hline
\end{tabular}

a: TPE is for Ton Petroleum Equivalent. 
Table 3: Estimation of the Probability To Install an Abatement Equipment

\begin{tabular}{lrrr}
\hline & Coef. $^{\text {a }}$ & Std Err & P-value \\
Constant & $-1.7060^{* * *}$ & 0.2130 & 0.0000 \\
Coke sector dummy & $0.7915^{* * *}$ & 0.2335 & 0.0010 \\
Chemistry sector dummy & $0.2800^{* *}$ & 0.1234 & 0.0230 \\
Total taxes - iron and steel & $0.0027^{* * *}$ & 0.0009 & 0.0030 \\
Total taxes - coke & 0.0006 & 0.0004 & 0.1700 \\
Total taxes - chemistry & 0.0002 & 0.0006 & 0.7570 \\
Total wages & $0.0047^{* *}$ & 0.0020 & 0.0160 \\
Total value of energy purchases (instrumented) & 0.0118 & 0.0083 & 0.1530 \\
Value Added & 0.0387 & 0.0795 & 0.6260 \\
Self-financing capacity / value added & $0.1016^{*}$ & 0.0563 & 0.0710 \\
Exceedance of $\mathrm{NO}_{2}$ standards & 0.3414 & 0.2780 & 0.2190 \\
Exceedance of SO ${ }_{2}$ standards & $0.3426 * *$ & 0.1579 & 0.0300 \\
& & & \\
Wald test of equal effects of total taxes across sectors (test statistic and p-value) & \\
& 5.77 & 0.056 & \\
Log-likelihood: -637.63 & & & \\
LR test (p-value): 114.08 (0.000) & & & \\
Number of observations: 1,386 & & & \\
\hline a: ***, **, * indicate significance at the 1, 5, 10\% level respectively. & &
\end{tabular}


Table 4: Estimation of the System of Emissions Equations

\begin{tabular}{|c|c|c|c|c|}
\hline & \multicolumn{2}{|c|}{$\mathrm{NO}_{\mathrm{x}}$ equation } & \multicolumn{2}{|c|}{$\mathrm{SO}_{2}$ equation } \\
\hline & Coef. $^{a}$ & Std Err & Coef. $^{\text {a }}$ & Std Err \\
\hline Constant & $286.304 * * *$ & 53.234 & 1.653 & 60.183 \\
\hline Emissions tax rate - iron and steel & $-27.944 * * *$ & 3.539 & $-56.822 * * *$ & 7.567 \\
\hline Emissions tax rate - coke & $-29.770 * * *$ & 7.118 & $-77.224 * * *$ & 19.705 \\
\hline Emissions tax rate - chemistry & $-20.047^{* * *}$ & 3.874 & $-36.681 * * *$ & 9.404 \\
\hline Decision to install an abatement equip - iron and steel & $4566.447^{* * *}$ & 400.694 & $10936.790 * * *$ & 763.285 \\
\hline Decision to install an abatement equip - coke & $2070.349 * * *$ & 534.380 & $5786.953^{* * *}$ & 1254.882 \\
\hline Decision to install an abatement equip - chemistry & $2660.309 * * *$ & 607.606 & $5587.320^{* * *}$ & 1387.560 \\
\hline Energy price & -61.254 & 70.390 & 135.309 & 131.595 \\
\hline Value added & -0.175 & 27.347 & 11.282 & 50.481 \\
\hline Self-financing capacity / value added & $-104.474 * * *$ & 15.477 & $-255.750 * * *$ & 28.969 \\
\hline Total wages & $-1.904 *$ & 1.086 & $-7.561 * * *$ & 2.027 \\
\hline Year 1990 & $-371.388 * * *$ & 72.838 & - & - \\
\hline Year 1991 & $-380.044 * * *$ & 71.778 & -27.464 & 77.334 \\
\hline Year 1992 & $-366.581 * * *$ & 69.254 & $-139.953 *$ & 78.343 \\
\hline Year 1993 & $-360.751 * * *$ & 70.726 & -106.142 & 77.558 \\
\hline Year 1994 & $-269.977 * * *$ & 61.042 & 8.191 & 81.442 \\
\hline Year 1995 & $-342.268 * * *$ & 58.127 & 68.214 & 85.379 \\
\hline Year 1996 & $-328.321 * * *$ & 57.765 & 30.595 & 85.175 \\
\hline Year 1997 & $-70.239 *$ & 37.537 & 28.086 & 86.150 \\
\hline Year 1998 & - & - & -3.194 & 90.199 \\
\hline After 1995 - coke & $241.384 * * *$ & 77.748 & $-642.707 * * *$ & 133.789 \\
\hline R-square & 0.11 & & 0.16 & \\
\hline \multicolumn{5}{|c|}{ Wald test of equal parameters across sectors (test statistic and p-value) } \\
\hline Tax rate & 9.44 & 0.0089 & 6.63 & 0.0363 \\
\hline Probability to install an abatement equipment & 22.00 & 0.0000 & 23.74 & 0.0000 \\
\hline \multicolumn{5}{|c|}{ Breusch-Pagan test of independent equations (test statistic and p-value) } \\
\hline Number of observations & & 1,386 & 120.094 & 0.0000 \\
\hline
\end{tabular}
a: ***, $* *, *$ indicate significance at the $1,5,10 \%$ level respectively. 
Table 5: Estimated Impacts of the Tax/Subsidy System

\begin{tabular}{|c|c|c|c|}
\hline & Elasticity to the tax & $\begin{array}{r}\text { Overall effect of tax on } \\
\text { emissions (ton) }\end{array}$ & $\begin{array}{l}\text { Overall effect of subsidy } \\
\text { on emissions (ton) }\end{array}$ \\
\hline & [95\% conf. int.] & [95\% conf. int.] & [95\% conf. int.] \\
\hline \multicolumn{4}{|l|}{$\mathrm{NO}_{\mathrm{x}}$} \\
\hline \multirow[t]{2}{*}{ Iron and steel } & -2.27 & -808 & 4,566 \\
\hline & {$[-2.83 ;-1.70]$} & {$[-1,008 ;-607]$} & {$[3,781 ; 5,352]$} \\
\hline \multirow[t]{2}{*}{ Coke } & -0.59 & -857 & 2,070 \\
\hline & {$[-0.86 ;-0.31]$} & {$[-1,259 ;-455]$} & {$[1,023 ; 3,118]$} \\
\hline \multirow[t]{2}{*}{ Chemistry } & -2.67 & -578 & 2,660 \\
\hline & {$[-3.68 ;-1.66]$} & {$[-797 ;-359]$} & {$[1,469 ; 3,851]$} \\
\hline \multicolumn{4}{|l|}{$\mathrm{SO}_{2}$} \\
\hline \multirow[t]{2}{*}{ Iron and steel } & -1.82 & $-1,486$ & 10,937 \\
\hline & {$[-2.29 ;-1.34]$} & {$[-1,874 ;-1,098]$} & {$[9,441 ; 12,433]$} \\
\hline \multirow[t]{2}{*}{ Coke } & -0.21 & -2.019 & 5,787 \\
\hline & {$[-0.31 ;-0.10]$} & {$[-3,029 ;-1,009]$} & {$[3,327 ; 8,246]$} \\
\hline \multirow[t]{2}{*}{ Chemistry } & -2.26 & -957 & 5,587 \\
\hline & [-3.40;-1.13] & {$[-1,438 ; 476]$} & {$[2,868 ; 8,307]$} \\
\hline
\end{tabular}

